\title{
Attentional Span Is Determined by Sport Discipline
}

\author{
Rafael E. Reigal ${ }^{1}{ }^{\circledR}$, Rocío Enríquez-Molina ${ }^{2}$, Sara Herrera-Robles ${ }^{2}$, Rocío Juárez-Ruiz de Mier ${ }^{3}{ }^{10}$,

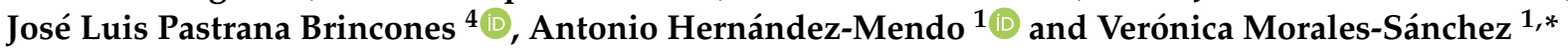

Citation: Reigal, R.E.; EnríquezMolina, R.; Herrera-Robles, S.;

\section{Juárez-Ruiz de Mier, R.; Pastrana}

Brincones, J.L.; Hernández-Mendo,

A.; Morales-Sánchez, V. Attentional

Span Is Determined by Sport

Discipline. Sustainability 2022, 14,

2524. https://doi.org/10.3390/

su14052524

Academic Editors: Filip Kukić,

Jay Dawes, Nenad Koropanovski

and Robin Orr

Received: 29 January 2022

Accepted: 18 February 2022

Published: 22 February 2022

Publisher's Note: MDPI stays neutral with regard to jurisdictional claims in published maps and institutional affiliations.

Copyright: (c) 2022 by the authors. Licensee MDPI, Basel, Switzerland. This article is an open access article distributed under the terms and conditions of the Creative Commons Attribution (CC BY) license (https:/ / creativecommons.org/licenses/by/ $4.0 /)$.
1 Department of Social Psychology, Social Work, Anthropology and East Asian Studies, University of Málaga, 29071 Málaga, Spain; rafareigal@uma.es (R.E.R.); mendo@uma.es (A.H.-M.)

2 Department of Human Physiology and Physical-Sports Education, University of Málaga, 29071 Málaga, Spain; rocioem@uma.es (R.E.-M.); saraherrera113@gmail.com (S.H.-R.)

3 Department of Evolutionary Psychology and Education, University of Málaga, 29071 Málaga, Spain; rjrm@uma.es

4 Department of Languages and Computer Science, University of Málaga, 29071 Málaga, Spain; pastrana@lcc.uma.es

* Correspondence: vomorales@uma.es

\begin{abstract}
Many studies have highlighted the impact of sport on cognitive functioning. However, more evidence is needed to explain which type of sport is more relevant. The main purpose of this study was to determine the level of attention span based on the type of sport practiced (open vs. closed). In addition, this problem was also analyzed based on gender and training hours. The study sample consisted of 547 participants (27.20\% male; $72.80 \%$ female), aged between 19 and 35 years old $(M=24.19 ; S D=3.74)$. The "Modrian Images" computerized test, hosted in MenPas Cell software(MenPas 1.0), was used to assess the attention span. The results showed that athletes playing open sports have a better attentional span than others playing closed sports. Moreover, this was also replicated when assessing by gender. Likewise, a greater number of hours in a week participating in sports is related to a better level of attentional span, being less determinant than the type of sport practiced. Data obtained suggest that playing open sports would be more related to the greater development of attention span than playing more closed sports.
\end{abstract}

Keywords: attention; cognitive functioning; exercise; gender

\section{Introduction}

Several studies have shown the existence of significant relationships between the regular practice of physical exercise and sport with cognitive functioning [1]. For example, more positive development in aspects such as language, working memory, processing speed, cognitive flexibility or inhibitory control has been observed when physical sport exercise is performed [2-4]. These functional changes would be modulated by a series of previous structural changes, which are associated with physical training, and they are, in parallel, associated with an increase in physical and sport skills [3].

Attention study has aroused great interest in recent years in this context, as well as well as in the field of cognitive abilities [2,5]. Exploring how attention is related to physical sport activity practice is relevant because it is an essential cognitive capacity for human functioning, and it is also linked to other cognitive skills that facilitate the processes of adaptation to the environment [6-8]. Among other issues, attention contributes to the selection and appropriate processing of information, facilitating effective responses such as elaboration and execution [4].

Attention is based on a very complex neurofunctional system [9]. Specifically, its neuroanatomical basis is based on a complex subcortical and cortical network of connections, where several structures, such as the activating reticular system, thalamus, limbic system, basal ganglia, posterior parietal cortex, prefrontal cortex, anterior cingulate cortex, superior midbrain colliculi and the cerebellum, are involved [9-18]. Different types of attention, such 
as wakefulness or alertness (arousal), attention span, selective or focal attention, shifting attention, serial attention, divided, dual or shared attention, readiness attention, sustained attention and inhibition of automatic responses, can be described $[9,15]$. Specifically, attentional span is defined as the ability to attend to a broad spectrum of stimuli at the same time, and it also can be defined as the number of tasks that can be performed simultaneously, retaining information in the memory in order to be used [5,15]. Three attentional span modalities can be differentiated: acoustic, auditory-verbal and visuospatial [12,16].

In addition, other research has analyzed the cognitive functioning of athletes in specific modalities such as tennis, football, archery, basketball, badminton or rugby, etc. [10,19]. One interesting question is how a type of physical sports practice could affect different cognitive skills $[4,20,21]$. Open sports, such as opposition or team sports, are considered to have a greater variability degree than closed sports, such as individual sports without opponents. This could imply that athletes practicing these modalities would have greater cognitive involvement and stimulation, because they must implement more complex mechanisms to perform effectively [22,23].

In particular, more open and variable sports require steadily making decisions, needing to handle a large amount of information and selecting which stimuli are relevant for the game actions. In addition, they must attend to a large set of stimuli, using this information to make their own decisions as appropriately as possible. Therefore, it is suggested that this type of sport modality could lead to better attentional development than other disciplines with lower stimulation [8,24]. For example, the study developed by [25] revealed that successful football players have a specific visual search strategy where a higher level of creativity was derived, so they are able to focus attention by short-duration fixations, providing useful information to interpret the situation. This ability of extracting important elements from the action environment, according to the author, allows them to respond even in a dynamic environment where many possibilities could happen.

As previously mentioned, attentional span allows for attention to be distributed over a broad set of elements [5,15]. In addition, attentional span capacity could be improved or developed by the practice of a certain strategy [5]. Therefore, it could be considered that sport practice could contribute to its improvement. Furthermore, this capacity could be trained and developed more intensely in this type of sport compared to other, more closed sports because it is necessary to attend to a wide range of stimuli in order to be used effectively in open sports.

Likewise, there are a number of tools to assess attentional span, such as digit retention tests (WISC-IV, WAIS), Corsi cubes, the Koppitz VADS test, word ranges, auditory-verbal span, the TOMAL visual selective test or the McCarthy test [26-32]. There are also other computerized instruments for attentional span training, such as the MenPas Assessment Platform Attentional Processes (www.menpas.com) (accessed on 15 January 2022) [33,34], BrainTrain ${ }^{\circledR}$ (Richmond, VA, USA), Cognifit (Nazrat Ilit, Israel) (www.cognifit.com) (accessed on 15 January 2022), Luminosity ${ }^{\circledR}$ (San Francisco, CA, USA) (www.lumosity.com) (accessed on 15 January 2022) or Brain Fitness (New York, NY, USA) (www.mindsparke. com) (accessed on 15 January 2022) [35-37].

Specifically, the MenPas software tool, which is used for online attention assessment and training, offers several applications based on attention (MenPas Cell, Grid, Attention Processes) [38]. Some of these tasks are Modrian-type tasks (Colors, Pictures, Pairs, Simon, Stroop), which are based on the Pieter Cornelius Mondrian creative styles and the scientific evidence indicating the activity shown up in the prestriate cortex when a person is stimulated by the combination of the colored grids in this instrument $[39,40]$. Specifically, MenPas Modrian is a software for short-term memory assessment, working memory and visual attention. The results obtained using this tool are automatically stored in the MenPas database, in order to be used later for automatic processing [33,34].

As more evidence is needed to explain which type of sport is more relevant, this study aimed to determine the attentional span differences between athletes practicing open-skill sports and athletes practicing closed-skill sports. Likewise, in order to limit any possible 
misleading factors and to ensure that the differences did not depend on other factors, they were also analyzed according to gender and sport participation duration (number of hours in a week).

\section{Materials and Methods}

\subsection{Participants}

The sample was composed of 547 participants, $72.80 \%(\mathrm{n}=398)$ female and $27.20 \%$ $(\mathrm{n}=149)$ male. Overall, 61.56\% $(\mathrm{n}=245)$ of females played closed sports and $38.44 \%$ $(\mathrm{n}=153)$ played open sports, while $40.27 \%(\mathrm{n}=60)$ of males played closed sports and $59.73 \%(n=89)$ played open sports. The age of the sample ranged from 19 to 35 years old $(M=24.19 ; S D=3.74)$. Inclusion criteria were (a) being between 19 and 35 years old; (b) engaging in regular sports practice; (c) taking the MenPas Modrian Images $3 \times 3$ matrix exercise in the MenPas platform, with a runtime of $30 \mathrm{~s}$ and $5 \mathrm{~s}$ of interference, and a difficulty level of 15 different items.

\subsection{Instruments and Measurements}

MenPas Modrian Images is a computerized tool hosted in MenPas Cell, software belonging to the online evaluation platform MenPas (www.menpas.com, accessed on 15 January 2022). This software was developed under the .Net platform, implemented in the C\# programming language using the Visual Studio Integrated Development Environment (IDE) programming [31,34,38]. MenPas Modrian Images is used to train and assess visual attention span ability but it also involves other cognitive aspects, such as short-term memory and working memory. When one logs into the MenPas program, one is asked for a username and password (Figure 1); then, one must set the size of the matrix (rows and columns), the number of different images to be used and the time for which one wishes the images to be displayed (Figure 2). When the program starts, the matrix appears, showing the images for a predefined time (Figure 3), and after that time, the images will be hidden. Then, the participant must point out where each image was located by, first, clicking with the mouse on an image (located below the matrix) (Figure 4) and then on the slot of the matrix where he/she thinks the image was placed (see https:/ /youtu.be/j-MeHd1aQfM, accessed on 15 January 2022). Successes and errors for each execution are recorded in the database, so they can be retrieved later.

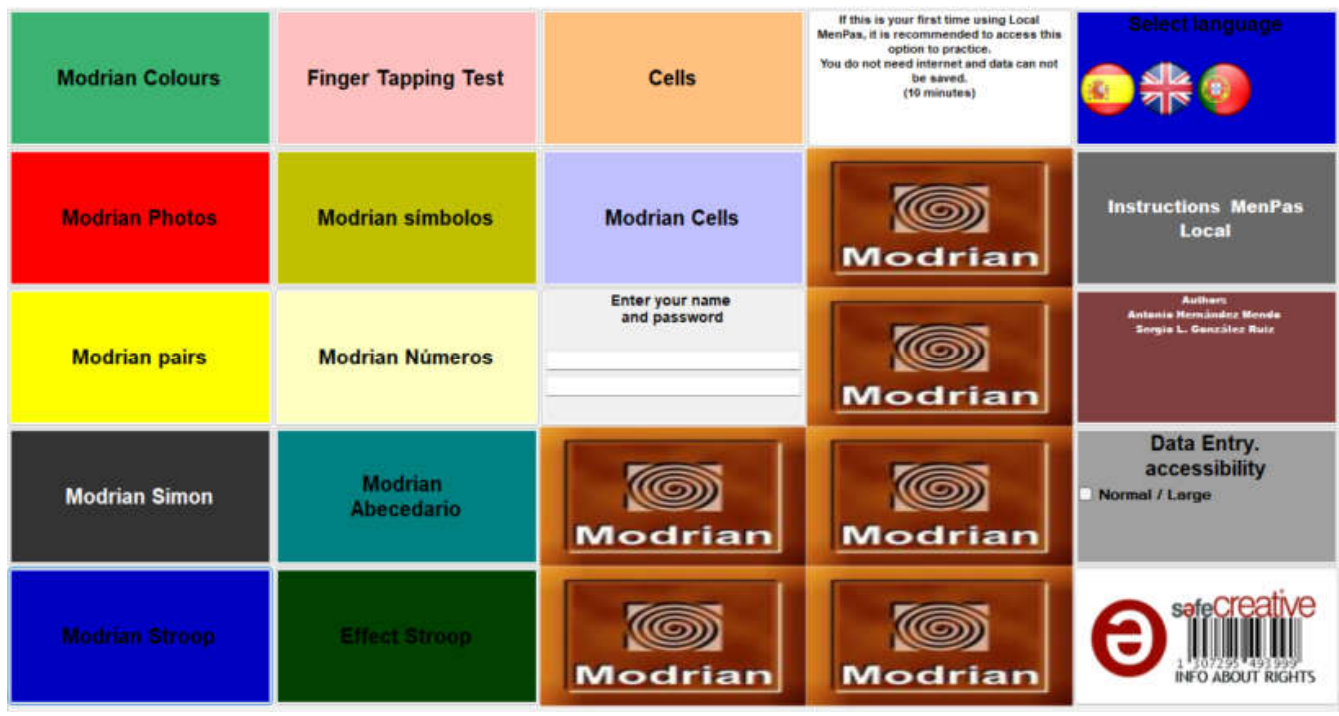

Figure 1. MenPas Modrian Images (running the application). 
Input data Modrians

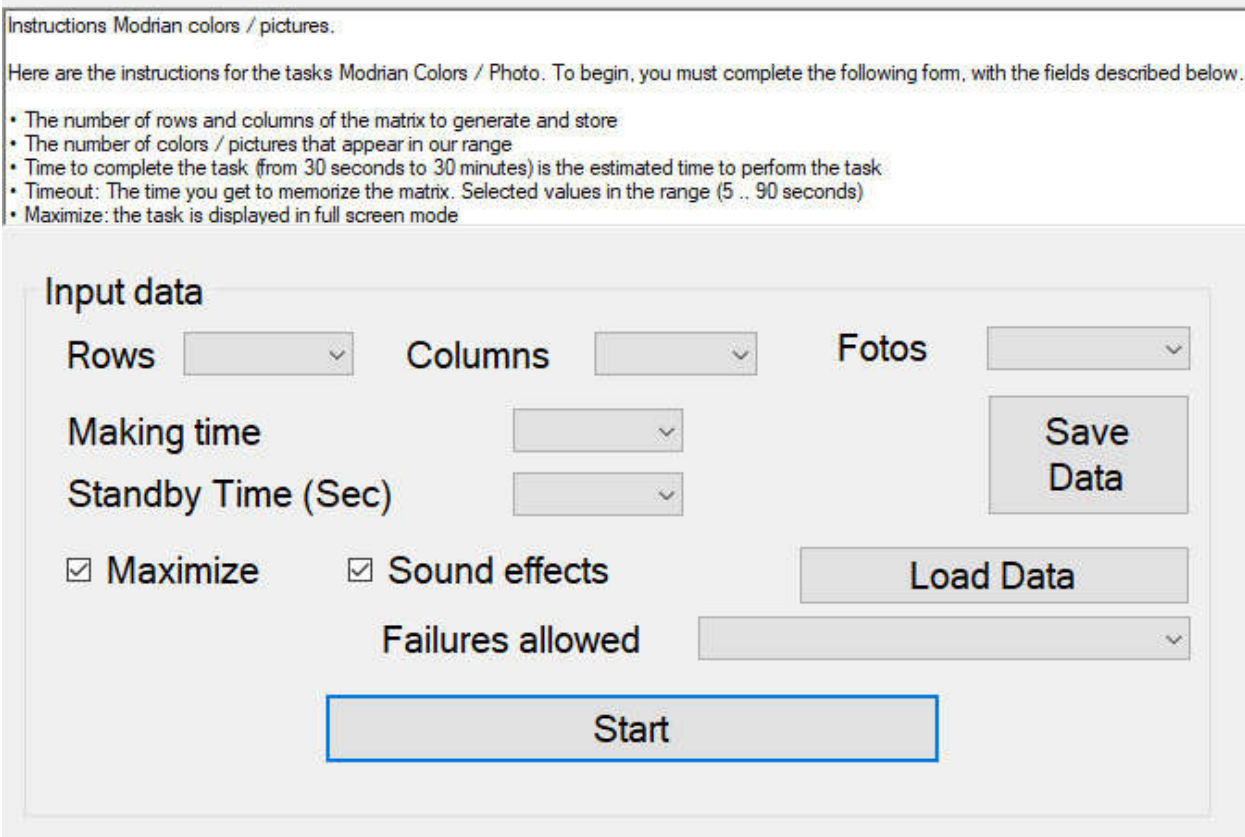

Figure 2. MenPas Modrian Images (defining properties and saving Modrian Images data).

\begin{tabular}{|c|c|c|}
\hline Pimeremaining:25 & Picture & Picture \\
A & B & A \\
\hline Picture & Picture \\
C & B & $\begin{array}{c}\text { Picture } \\
\text { E }\end{array}$ \\
\hline Picture & Picture \\
D & E & Picture \\
& A \\
\hline
\end{tabular}

Figure 3. MenPas Modrian Images (pictures start to appear when clicked).

\subsection{Procedure}

The research team collected data from multiple MenPas Modrian Images executions between 2019 and 2020. The request to participate in the study and its tutorial were disseminated by the MenPas platform, allowing participants to perform the exercises online. These data were stored in the MenPas online platform database. Informed consent is obtained by the platform when any user registers him/herself and fills in his/her personal information. Participants are informed, during the registration process, about which data are being collected, who will have access to them and how they will be used. As the consent approval is mandatory for user registration, processing and storing scores is always known and approved. The ethical principles of the Helsinki declaration [41] were respected throughout the research process. The study was also approved by the ethics committee (CEUMA, no. 243, 19-2015-H) of the University of Malaga (Spain). 


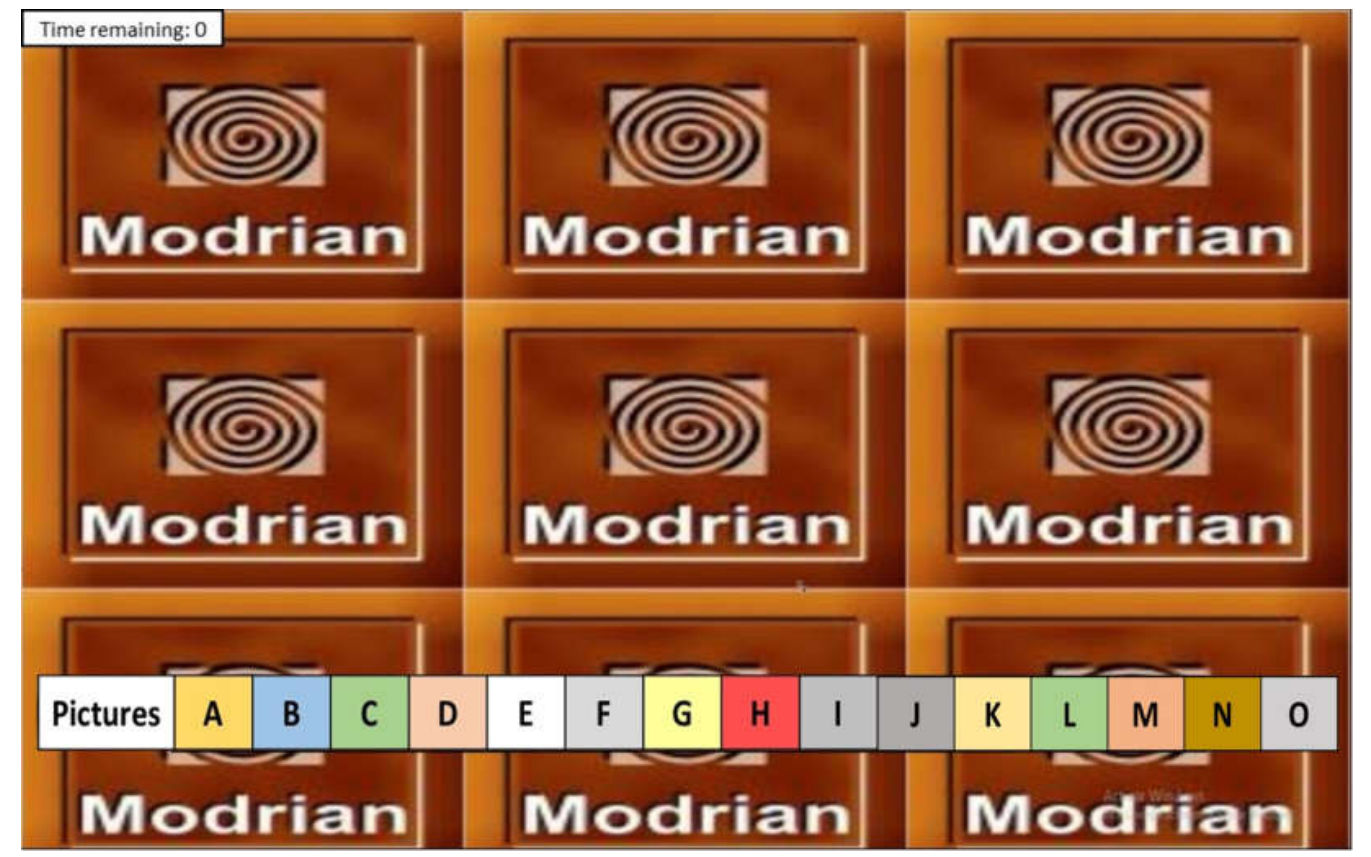

Figure 4. MenPas Modrian Images (images will disappear and will be placed at the bottom array. The user must click on the space where they were located after clicking on them).

\subsection{Data Analysis}

Descriptive and inferential analyses of data were performed. The standardized coefficient of skewness and kurtosis was estimated in order to assess the normality of the variables, as well as the Kolmogorov-Smirnov test. The Mann-Whitney U and KruskalWallis tests were used to determine possible differences between groups. Cluster analysis (k-means) was performed to classify the participants into groups according to the type of sport and the number of weekly hours of physical practice. The level of significance was set at $p<0.05$. Likewise, the effect size was calculated using Cohen's $d$. In addition, Bonferroni correction for multiple comparisons was performed to the minimize type I error. The SPSS statistical program was used for the statistical treatment of the data (SPSS Inc. v.25.0, Chicago, IL, USA).

\section{Results}

Table 1 shows the results obtained in Modrian Images depending on the sports discipline practiced. It also shows the number of hours per week dedicated to sports practice. The table shows the mean, standard deviation, skewness, kurtosis and KolmogorovSmirnov values. As can be seen, there was no normal distribution in the data regarding the range of skewness and kurtosis, and the statistical analysis yielded values between -1.14 and 1.45 , as well as between -1.29 and 4.77 , respectively. The Mann-Whitney U test was performed for comparison between groups (the $p$-values after Bonferroni correction were as follows: $p<0.0125, p<0.0025$ and $p<0.00025$ ). There were statistically significant differences between groups in the number of physical practice hours in all the analyzed variables. The group that practiced open sports performed the sport activity for fewer hours $(Z=-5.49 ; p<0.00025$, Cohen's $d=0.50,95 \% \mathrm{CI}(0.33,0.68))$, and they had greater success in the attentional amplitude test $(Z=-2.51 ; p<0.0125$, Cohen's $d=0.17,95 \% \mathrm{CI}$ $(-0.01,0.34))$, as well as a smaller number of errors $(Z=-2.68 ; p<0.0125$, Cohen's $d=0.12$, $95 \%$ CI $(-0.05,0.29))$ and number of blank responses $(Z=-2.51 ; p<0.0125$, Cohen's $d=0.16,95 \%$ CI $(-0.01,0.33))$. 
Table 1. (a) Weekly hours of sports practice, as well as hits, errors and blank answers in the Modrian Images test, according to the sport practiced. (b) Differences depending on the sport practiced.

\begin{tabular}{ccccccccccc}
\hline & \multicolumn{4}{c}{ Closed Sports } & \multicolumn{4}{c}{ Open Sports } \\
& $\boldsymbol{M}$ & $\boldsymbol{S D}$ & $\boldsymbol{A}$ & $\boldsymbol{K}$ & $\boldsymbol{K}-\boldsymbol{S}$ & $\boldsymbol{M}$ & $\boldsymbol{S} \boldsymbol{A}$ & $\boldsymbol{K}$ & $\boldsymbol{K}-\boldsymbol{S}$ \\
\hline Sports practice & 7.22 & 3.33 & -0.52 & -1.29 & $0.31^{* * *}$ & 5.67 & 2.71 & 0.63 & -0.52 & $0.18^{* * *}$ \\
Hits & 5.32 & 2.67 & -0.40 & -0.79 & $0.12^{* * *}$ & 5.78 & 3.08 & -0.54 & -1.01 & $0.17^{* * *}$ \\
Errors & 1.54 & 0.72 & -1.14 & 0.01 & $0.40^{* * *}$ & 1.42 & 1.25 & 1.45 & 4.77 & $0.26^{* * *}$ \\
Blank answers & 3.68 & 2.67 & 0.40 & -0.79 & $0.12^{* * *}$ & 3.22 & 3.08 & 0.54 & -1.01 & $0.17^{* * *}$ \\
\hline
\end{tabular}

Note: $M=$ Mean; $S D=$ Standard Deviation; $A$ = Skewness; $K=$ Kurtosis; $K-S=$ Kolmogorov-Smirnov. ${ }^{* * *} p<0.001$.

Table 2 shows the results obtained in Modrian Images according to the sport practiced and gender. It also shows the number of hours per week dedicated to sports practice. The table shows the mean, standard deviation, skewness, kurtosis and Kolmogorov-Smirnov values. As can be seen, there was no normal distribution in the data for the different variables. Likewise, the values of skewness $(-1.26$ and 0.48$)$ and kurtosis $(-1.36$ and $0.18)$ were adequate. The Mann-Whitney $U$ test was performed for comparison between groups (the $p$-values after Bonferroni correction were as follows: $p<0.0125, p<0.0025$ and $p<0.00025)$. There were statistically significant differences between groups in the number of hours of sports practice for females $(Z=-3.96 ; p<0.001$, Cohen's $d=0.44,95 \% \mathrm{CI}(0.24$, $0.64)$ ) and males $(Z=-3.85 ; p<0.001$, Cohen's $d=0.62,95 \%$ CI $(0.28,0.95))$ among the groups of athletes. In addition, female athletes playing open sports had a lower number of misses $(Z=-2.53 ; p<0.05$, Cohen's $d=0.13,95 \%$ CI $(-0.07,0.33))$.

Table 2. (a) Weekly hours of sports practice, hits, errors and blank answers in the Modrian Images test, according to the sport practiced and gender. (b) Differences depending on the sport practiced and gender.

\begin{tabular}{|c|c|c|c|c|c|c|c|c|c|c|}
\hline & \multicolumn{5}{|c|}{ Closed Sports } & \multicolumn{5}{|c|}{ Open Sports } \\
\hline & $M$ & $S D$ & $A$ & $K$ & $K-S$ & $M$ & $S D$ & $A$ & $K$ & $K-S$ \\
\hline \multicolumn{11}{|l|}{ (Female) } \\
\hline Sports practice & 7.26 & 3.45 & -0.56 & -1.36 & $0.34^{* * *}$ & 5.87 & 2.62 & 0.46 & -1.01 & $0.19^{* * *}$ \\
\hline Hits & 5.43 & 2.64 & -0.48 & -0.66 & $0.13^{*}$ & 5.78 & 3.23 & -0.53 & -1.16 & $0.19^{* * *}$ \\
\hline Errors & 1.56 & 0.69 & 1.26 & 0.18 & $0.41^{* * *}$ & 1.43 & 1.37 & 1.59 & 4.57 & $0.25^{* * *}$ \\
\hline $\begin{array}{l}\text { Blank answers } \\
\text { (Male) }\end{array}$ & 3.57 & 2.64 & 0.48 & -0.66 & $0.13^{*}$ & 3.22 & 3.23 & 0.53 & -1.16 & 0.19 * \\
\hline Sports practice & 7.08 & 2.81 & -0.22 & -0.79 & $0.16^{* * *}$ & 5.34 & 2.84 & 0.94 & 0.35 & $0.16^{* * *}$ \\
\hline Hits & 4.85 & 2.79 & -0.11 & -1.09 & $0.12 * * *$ & 5.76 & 2.82 & -0.56 & -0.64 & $0.13 *$ \\
\hline Errors & 1.50 & 0.83 & -0.81 & -0.48 & $0.37^{* * *}$ & 1.40 & 1.03 & 0.70 & 3.26 & $0.29 * * *$ \\
\hline Blank answers & 4.15 & 2.79 & 0.11 & -1.09 & $0.12^{* * *}$ & 3.24 & 2.82 & 0.56 & -0.64 & $0.13 *$ \\
\hline
\end{tabular}

Differences in cognitive performance based on the duration of sports practice by type of sport were determined. For this, k-mean cluster analyses were performed according to the number of hours practiced and segmented by type of sport. Four groups were generated (group 1, $\mathrm{n}=128$, closed sports and fewer hours of physical practice; group 2, $\mathrm{n}=177$, closed sports and greater number of hours of physical practice; group $3, \mathrm{n}=175$, open sports and fewer hours of physical practice; group $4, n=67$, open and greater number of hours of physical practice). All cases were correctly classified, as the maximum distance between each case and the center of its group was always less than the distance between clusters. Table 3 shows the results obtained in weekly physical practice, as well as the number of hits, errors and blank answers in the Modrian Images test according to the clusters generated. The table shows the mean, standard deviation, skewness, kurtosis and Kolmogorov-Smirnov values. As can be seen, there was no normal distribution of the 
data. Regarding the range of skewness and kurtosis, the statistical analysis yielded values between -1.16 and 1.52 , as well as between -1.61 and 4.61 , respectively.

Table 3. The number of weekly hours of sports practice is shown, as well as the hits, misses and blank answers in the Modrian Images test, according to the clusters generated.

\begin{tabular}{|c|c|c|c|c|c|c|c|}
\hline Sport & Cluster & & $M$ & $S D$ & $A$ & $K$ & $K-S$ \\
\hline \multirow[t]{9}{*}{ Closed } & $1(\mathrm{n}=128)$ & Sports practice (hours) & 3.59 & 1.66 & 0.10 & -1.18 & $0.15^{* * *}$ \\
\hline & & Hits & 4.73 & 2.82 & -0.18 & -1.16 & $0.12^{* * *}$ \\
\hline & & Errors & 1.51 & 0.74 & -1.14 & -0.22 & $0.40^{* * *}$ \\
\hline & & Blank answers & 4.27 & 2.82 & 0.18 & -1.20 & $0.12 * * *$ \\
\hline & $2(\mathrm{n}=177)$ & Sport practice & 9.85 & .80 & -0.61 & 2.99 & $0.45^{* * *}$ \\
\hline & & Hits & 5.74 & 2.49 & -0.54 & -0.38 & $0.12^{* * *}$ \\
\hline & & Errors & 1.57 & 0.71 & -1.16 & 0.23 & $0.41^{* * *}$ \\
\hline & & Blank answers & 3.26 & 2.42 & 0.54 & -0.38 & $0.12^{* * *}$ \\
\hline & $3(n=175)$ & Sports practice (hours) & 4.21 & 1.35 & -0.21 & -1.07 & $0.18^{* * *}$ \\
\hline \multirow[t]{7}{*}{ Open } & & Hits & 5.53 & 3.17 & -0.44 & -1.17 & $0.15^{* * *}$ \\
\hline & & Errors & 1.58 & 1.33 & 1.52 & 4.61 & $0.29 * * *$ \\
\hline & & Blank answers & 3.47 & 3.17 & 0.44 & -1.14 & $0.15^{* * *}$ \\
\hline & $4(\mathrm{n}=67)$ & Sport practice & 9.49 & 1.27 & 0.63 & 1.22 & $0.31^{* * *}$ \\
\hline & & Hits & 6.43 & 2.77 & -0.80 & -0.42 & $0.21^{* * *}$ \\
\hline & & Errors & 1.01 & 0.93 & 0.09 & -1.61 & $0.27^{* * *}$ \\
\hline & & Blank answers & 2.57 & 2.86 & 0.77 & -0.48 & $0.21^{* * *}$ \\
\hline
\end{tabular}

Note: $M=$ Mean; $S D=$ Standard Deviation; $A=$ Skewness; $K=$ Kurtosis; $K-S=$ Kolmogorov-Smirnov. ${ }^{* * *} p<0.001$.

Kruskal-Wallis analyses indicated statistically significant differences between clusters (the $p$-values after Bonferroni correction were as follows: $p<0.0083, p<0.0016$ and $p<0.00016)$ in terms of hours of sport practice $\left(\chi^{2}=429.02 ; p<0.00016\right)$, number of hits $\left.\chi^{2}=18.60 ; p<0.0016\right)$, errors $\left(\chi^{2}=19.57 ; p<0.0016\right)$ and blank responses $\left(\chi^{2}=17.98\right.$; $p<0.0016$ ). Table 4 shows the comparisons between groups (Mann-Whitney $\mathrm{U}$ ) for the hours of sports practice, as well as hits, errors and blank answers, among the generated clusters.

Table 4. Differences in the number of weekly hours of sports practice, as well as hits, misses and blank answers in the Modrian Images test, as a function of the clusters generated.

\begin{tabular}{|c|c|c|c|c|c|c|}
\hline & \multicolumn{6}{|c|}{ Mann-Whitney U } \\
\hline & 1 vs. 2 & 1 vs. 3 & 1 vs. 4 & 2 vs. 3 & 2 vs. 4 & 3 vs. 4 \\
\hline \multicolumn{7}{|l|}{ Sport practice } \\
\hline$Z$ & -15.86 & -3.33 & -11.57 & -16.92 & -3.07 & -12.16 \\
\hline$p$ & $<0.00016$ & $<0.0016$ & $<0.00016$ & $<0.00016$ & $<0.0083$ & $<0.00016$ \\
\hline Cohen's d & 5.01 & 0.42 & 3.84 & 5.09 & 0.38 & 3.97 \\
\hline CI & $(4.60-5.53)$ & $(0.19-0.65)$ & (3.35-4.32) & $(4.66-5.52)$ & $(0.09-0.66)$ & $(3.52-4.43)$ \\
\hline \multicolumn{7}{|l|}{ Hits } \\
\hline Z & -3.02 & - & -4.06 & - & - & - \\
\hline$p$ & $<0.0083$ & - & $<0.00016$ & - & - & - \\
\hline Cohen's d & 0.38 & - & 0.61 & - & - & - \\
\hline$C I$ & $(0.15-0.61)$ & - & $(0.30-0.91)$ & - & - & - \\
\hline \multicolumn{7}{|l|}{ Erros } \\
\hline Z & - & - & -3.76 & - & -4.48 & -3.08 \\
\hline$p$ & - & - & $<0.0016$ & - & $<0.00016$ & $<0.0083$ \\
\hline Cohen's d & - & - & 0.62 & - & 0.72 & 0.46 \\
\hline$C I$ & - & - & $(0.31-0.92)$ & - & $(0.43-1.01)$ & $(0.18-0.75)$ \\
\hline \multicolumn{7}{|l|}{ Blank answers } \\
\hline Z & -3.04 & - & -4.03 & - & - & - \\
\hline$p$ & $<0.0083$ & - & $<0.00016$ & - & - & - \\
\hline Cohen's d & 0.39 & - & 0.59 & - & - & - \\
\hline$C I$ & $(0.16-0.62)$ & - & $(0.29-0.90)$ & - & - & - \\
\hline
\end{tabular}




\section{Discussion}

The aim of this study was to determine any difference in attentional span between athletes playing closed sports and athletes playing open sports. In addition, analyses have been carried out according to gender and the amount of weekly training hours, in order to assess the biases of any possible misleading factor. A computerized tool belonging to the Attentional Processes software of the evaluation platform MenPas 1.0, called Modrian Images, has been used to analyze the level of attentional span. The results found show a lower level of attentional span in those athletes playing closed disciplines compared to others playing open modalities. However, gender was found to be a less significant factor. Despite this, the number of weekly hours of physical practice showed significant differences for each type of sport, which suggests that, combined with the type of sport, it is a variable that determines the attentional capacity of athletes.

Firstly, differences have been observed according to the type of sport practiced. Athletes playing open sports showed a greater attentional capacity than those playing closed sports. These differences have been found for hits, errors and blank answers. In other words, participants who took part in open sports were able to attend to a greater number of stimuli and to perform tasks with greater precision. The findings are in line with previous studies that showed how the type of sport could influence the development of attentional functioning, and specifically those sports subject to greater variability during practice [42].

This suggests that athletes in open modalities could be subjected to greater attentional training during their training and competitions. Thus, they would attend to a greater number of stimuli, since they are engaging in more open and variable game dynamics, where there is a greater amount of information. In this way, these circumstances could have an impact on cognitive development as there is greater stimulation $[41,43]$. In the studies conducted by [44,45], it was highlighted that, when practicing some type of open sport, athletes are continuously attending to different stimuli; this could be exerting an impact on the development of their attentional abilities [46].

In general, there are many studies showing how the practice of continuous physical sports activity has a positive impact on attentional development [2,4]. In this work, it has been observed that the number of weekly hours of physical practice determines statistically significant differences for each group of athletes, which suggests that it could be influencing the development of their attention capacity. However, some aspects should be noted. Looking at the group of closed sports athletes, the group composed of athletes performing a greater number of weekly physical exercise hours showed a greater number of correct answers and fewer blank responses. In addition, looking at the group of open sports athletes, the group composed of athletes engaging in the most weekly physical practice only scored better in terms of errors. However, when the groups of athletes were compared based on the amount of weekly physical practice, there were not so many differences between groups. In any case, it should be noted that the greatest differences appeared between the group of closed sports and less physical practice and the group of open sports and more physical practice. These results suggest that both variables-time of weekly physical practice and type of sport practiced-condition the development of the evaluated attentional capacity $[12,47]$.

Secondly, it can be observed that gender did not have any influence on the results, as some of the previous research carried out by different researchers has demonstrated. In the study performed by Ducrocq et al. [21], it was found that participants showed a high degree of attention deficit and hyperactivity disorders such as ADHD. Their study was developed by observing fencing training with 20 children aged between twelve and fourteen years, where it was concluded that the attention paid by fencing athletes to strategies positively influences concentration, sustained attention and tactical execution. Likewise, another study [48] highlighted the relationship between sport experience and perceptual and cognitive skills, without gender modifying the results. This study involved 154 people who underwent cognitive, memory and visuospatial attention tests, and concluded that there is a relationship between sport and cognition, in such a way that athletes with high 
levels of performance recorded a higher speed of cognitive processing and visual attention, compared to people not considered athletes [49,50].

Gender did not condition the results. However, there were very few differences between athletes in open and closed sports when each gender was analyzed separately. A possible reason for this fact is the amount of physical practice performed by each of the groups. As can be seen, closed sports athletes trained for more hours per week, including both men and women. This also occurred when the entire sample was analyzed; the segmentation into smaller groups and the influence of training time were able to neutralize the statistical significance. In addition, the Bonferroni correction was used to limit type I statistical errors. This, which is important in order not to generate false positives, also limits the strength of the contrasts and reduces the probability of finding greater statistically significant differences.

There is research linking gender difference with sport $[15,18]$, related to the athlete's experience and the number of weekly hours of sport practice. Thus, there are some studies that suggest that, in fast ball sports, such as volleyball, women would benefit from a higher cognitive level because of their sport experience [50]. As can be seen in the aforementioned studies, all of them suggest that the impact of physical sports activity on cognitive development is not an aspect modulated by gender, but modulated by the amount and type of sports practice performed, as well as training time [7,51].

This study has some limitations. It is not possible to establish causal relationships between the study variables. Therefore, it would be interesting to carry out longitudinal or quasi-experimental studies to determine with greater weight whether the type of sport generates greater attentional development in athletes. In addition, it would be appropriate to include groups that do not engage in physical sport activity, which could also help to determine the differences between practicing and not practicing sports. In addition, it would be appropriate to explore other cognitive abilities in order to determine whether the impact of open vs. closed sport is reproduced in other cognitive manifestations. Likewise, as a future line of research, it is proposed to analyze differences between types of open sports-for example, between football and basketball, between tennis and paddle tennis or between football and tennis- to determine whether there could be differences between open and semi-open modalities, or in different types of technical-tactical development.

\section{Conclusions}

In conclusion, the results obtained in the present research indicate that athletes playing sports with greater variability and regularly training for more hours per week, regardless of gender, have a higher level of attentional span than athletes practicing closed modalities and who spend less time training.

Author Contributions: R.E.R., R.E.-M., S.H.-R., R.J.-R.d.M., J.L.P.B., A.H.-M. and V.M.-S. participated in the study design and data collection, performed statistical analyses and contributed to the interpretation of the results, wrote the manuscript and approved the final manuscript as presented. All authors made substantial contributions to the final manuscript. All authors have read and agreed to the published version of the manuscript.

Funding: This research received no external funding.

Institutional Review Board Statement: The study was conducted in accordance with the Declaration of Helsinki, and approved by the Institutional Review Board (or Ethics Committee) of University of Málaga (CEUMA, no. 243, 19-2015-H).

Informed Consent Statement: Informed consent was obtained from all subjects involved in the study.

Data Availability Statement: Not applicable.

Conflicts of Interest: The authors declare no conflict of interest. 


\section{References}

1. Gallego, V.; Reigal, R.E.; Hernández-Mendo, A.; Juárez-Ruiz de Mier, R. Efectos de la actividad física sobre el funcionamiento cognitivo en preadolescentes. Apunts 2015, 121, 20-27. [CrossRef]

2. Xue, Y.; Yang, Y.; Huang, T. Effects of chronic exercise interventions on executive function among children and adolescents: A systematic review with meta-analysis. Brit. J. Sport. Med. 2019, 53, 1397. [CrossRef] [PubMed]

3. Esteban-Cornejo, I.; Cadenas-Sánchez, C.; Contreras-Rodriguez, O.; Verdejo-Roman, J.; Mora-Gonzalez, J.; Migueles, J.H.; Ortega, F.B. A whole brain volumetric approach in overweight/obese children: Examining the association with different physical fitness components and academic performance. The ActiveBrains project. NeuroImage 2017, 159, 346-354. [CrossRef] [PubMed]

4. Liu, J.H.; Alderman, B.L.; Song, T.F.; Chen, F.T.; Hung, T.M.; Chang, Y.K. A randomized controlled trial of coordination exercise on cognitive function in obese adolescents. Psychol. Sport. Exerc. 2018, 34, 29-38. [CrossRef]

5. Alves, H.; Voss, M.; Boot, W.; Deslandes, A.; Cossich, V.; Inacio-Salles, J.; Kramer, A. Perceptual-Cognitive Expertise in Elite Volleyball Players. Front. Psychol. 2013, 4, 36. [CrossRef]

6. Kirk, D. Physical education-as-health promotion: Recent developments and future issues. Educ. Health. 2018, 36, 70-75.

7. Ploughman, M. Exercise is brain food: The effects of physical activity on cognitive function. Dev. Neurorehabil. 2008, 11, 236-240. [CrossRef]

8. Orozco-Calderón, G.; Ruz-Santos, I. Decremento de las funciones ejecutivas en deportistas. Cienc. Futuro 2019, 9, 116-133.

9. Carrasco, M.; Barbot, A. Spatial attention alters visual appearance. Curr. Opin. Psychol. 2019, 29, 56-64. [CrossRef]

10. Amon, M.J. Visual attention in mixed-gender groups. Front. Psychol. 2015, 5, 1569. [CrossRef]

11. Best, J.R. Effects of physical activity on children's executive function: Contributions of experimental research on aerobic exercise. Dev. Rev. 2010, 30, 331-551. [CrossRef] [PubMed]

12. Jangmo, A.; Stålhandske, A.; Chang, Z.; Chen, Q.; Almqvist, C.; Feldman, I.; Larsson, H. Attention-Deficit/Hyperactivity Disorder, School Performance, and Effect of Medication. J. Am. Acad. Child. 2019, 58, 423-432. [CrossRef] [PubMed]

13. Nussenbaum, K.; Amso, D.; Markant, J. When increasing distraction helps learning: Distractor number and content interact in their effects on memory. Atten. Percept. Psychol. 2017, 79, 2606-2619. [CrossRef] [PubMed]

14. Mirdamadi, J.L.; Suzuki, L.Y.; Meehan, S.K. Attention modulates specific motor cortical circuits recruited by transcranial magnetic stimulation. Neuroscience 2017, 359, 151-158. [CrossRef] [PubMed]

15. Etchepareborda, M.C.; Abad-Mas, L. Sustrato biológico y evaluación de la atención. Rev. Neurol. Clin. 2001, 2, 113-124.

16. Colmenero, J.M.; Catena, A.; Fuentes, L.J. Atención visual: Una revisión sobre las redes atencionales del cerebro. An. Psicol. 2001, $17,45-67$.

17. Petersen, S.E.; Posner, M.I. The Attention System of the Human Brain: 20 Years After. Annu. Rev. Neurosci. 2012, 35, 73-89. [CrossRef]

18. Castillo-Villar, M.D. La Atención [The Attention]; Pirámide: Madrid, Spain, 2009.

19. Meng, F.W.; Yao, Z.F.; Chang, E.C.; Chen, Y.L. Team sport expertise shows superior stimulus-driven visual attention and motor inhibition. PLoS ONE 2019, 14, e0217056. [CrossRef]

20. Estévez-González, A.; García-Sánchez, C.; Junqué, C. La atención: Una compleja función cerebral [Attention: A complex brain function]. Rev. Neurol. 1997, 25, 1989-1997.

21. Ducrocq, E.; Wilson, M.; Vine, S.; Derakshan, N. Training attentional control improves cognitive and motor task performance. J. Sport Exerc. Psychol. 2016, 38, 521-533. [CrossRef]

22. Colcombe, S.J.; Erickson, K.I.; Scalf, P.E.; Kim, J.S.; Prakash, R.; McAuley, E.; Kramer, A.F. Aerobic Exercise Training Increases Brain Volume in Aging Humans. J. Gerontol. Ser. A 2006, 61, 1166-1170. [CrossRef] [PubMed]

23. Romeas, T.; Guldner, A.; Faubert, J. 3D-Multiple Object Tracking training task improves passing decision-making accuracy in soccer players. Psychol. Sport. Exerc. 2016, 22, 1-9. [CrossRef]

24. Fleddermann, M.T.; Heppe, H.; Zentgraf, K. Off-court generic perceptual-cognitive training in elite volleyball athletes: Taskspecific effects and levels of transfer. Front. Psychol. 2019, 10, 1599. [CrossRef] [PubMed]

25. Lundgren, T.; Reinebo, G.; Löf, P.O.; Näslund, M.; Svartvadet, P.; Parling, T. The Values, Acceptance, and Mindfulness Scale for Ice Hockey: A Psychometric Evaluation. Front. Psychol. 2018, 9, 1794. [CrossRef] [PubMed]

26. Verburgh, L.; Scherder, E.J.A.; van Lange, P.A.M.; Oosterlaan, J. Executive functioning in highly talented soccer players. PLoS ONE 2014, 9, e91254. [CrossRef]

27. Williams, M.; Ford, P.; Eccles, D.; Ward, P. Perceptual-cognitive expertise in sport and its acquisition: Implications for applied cognitive psychology. Appl. Cogn. Psych. 2011, 25, 432-442. [CrossRef]

28. Roca, A.; Ford, P.R.; Memmert, D. Creative decision making and visual search behavior in skilled soccer players. PLoS ONE 2018, 13, e0199381. [CrossRef]

29. Koppitz, E. La Prueba de Extensión de Dígitos Auditivos Visuales [The Visual Auditory Digit Span Test]; Grune y Stratton: New York, NY, USA, 1977.

30. Madoz-Gúrpide, A.; Ochoa-Mangado, E. Alteraciones de funciones cognitivas y ejecutivas en pacientes dependientes de cocaína: Estudio de casos y controles [Alterations of cognitive and executive functions in cocaine-dependent patients: A case-control study]. Rev. Neurol. 2012, 54, 199-208.

31. Wechsler, D. Escala de Inteligencia de Wechsler Para Adultos-III (WAIS-III) [Wechsler Adult Intelligence Scale-III (WAIS-III)]; TEA: Madrid, Spain, 1999. 
32. Wechsler, D. Manual de Aplicación y Corrección del WISC-IV [WISC-IV Application and Correction Manual]; TEA: Madrid, Spain, 2005.

33. Reynolds, C.M. Prueba de Memoria y Aprendizaje [Memory and Learning Test]; TEA: Madrid, Spain, 2001.

34. Soprano, A. Cómo Evaluar la Atención y Las Funciones Ejecutivas en Los Niños y Adolescentes [How to Evaluate Attention and Executive Functions in Children and Adolescents]; Paidós: Buenos Aires, Argentina, 2009.

35. González-Ruiz, S.; Dominguez-Alfonso, R.; Chica-Merino, E.; Pastrana-Brincones, J.L.; Hernández-Mendo, A. Una plataforma virtual para la evaluación e investigación on-line: Menpas [A virtual platform for on-line assessment and research: Menpas.]. Cuad. Psicol. Deporte 2018, 18, 26-48. [CrossRef]

36. González-Ruiz, S.; Hernández-Mendo, A.; Pastrana-Brincones, J.L. Herramienta Software para la Evaluación Psicosocial de Deportistas y Entornos Deportivos [Software Tool for the Psychosocial Assessment of Athletes and Sport Environments]. 2010. Available online: http:/ / www.efdeportes.com/efd144/evaluacion-psicosocial-de-deportistas.htm (accessed on 15 July 2021).

37. Kletzel, S.L.; Cary, M.P., Jr.; Ciro, C.; Berbrayer, D.; Dawson, D.; Hoffecker, L.; Heyn, P.C. Brain Gaming: A user's product guide for the clinician. Arch. Phys. Med. Rehabil. 2016, 97, 1399-1400. [CrossRef]

38. Rabiner, D.L.; Murray, D.W.; Skinner, A.T.; Malone, P.S. A Randomized Trial of Two Promising Computer-Based Interventions for Students with Attention Difficulties. J. Abnorm. Child. Psych. 2010, 38, 131-142. [CrossRef] [PubMed]

39. Shatil, E.; Mikulecká, J.; Bellotti, F.; Bureš, V. Novel Television-Based Cognitive Training Improves Working Memory and Executive Function. PLoS ONE 2014, 9, e101472. [CrossRef]

40. Morrison, G.E.; Simone, C.M.; Ng, N.F.; Hardy, J.L. Reliability and validity of the neurocognitive performance test, a web-based neuropsychological assessment. Front. Psychol. 2015, 6, 1652. [CrossRef] [PubMed]

41. World Medical Association. World Medical Association Declaration of Helsinki: Ethical principles for medical research involving human subjects. J. Am. Med. Assoc. 2013, 310, 2191-2194. [CrossRef] [PubMed]

42. Hernández-Mendo, A.; Ramos-Pollán, R. El uso de la Informática en la Psicología del Deporte [The Use of Informatics in Sport Psychology], 2000, 19. Available online: https://www.efdeportes.com/efd19/infpsi.htm (accessed on 12 July 2021).

43. Zeki, S.; Shipp, S. The functional logic of cortical connections. Nature 1988, 335, 311-317. [CrossRef]

44. Brenton, J.; Müller, S.; Harbaugh, A.G. Visual-perceptual training with motor practice of the observed movement pattern improves anticipation in emerging expert cricket batsmen. J. Sport. Sci. 2019, 37, 2114-2121. [CrossRef]

45. Hagman, E.; Danielsson, P.; Brandt, L.; Svensson, V.; Ekbom, A.; Marcus, C. Childhood obesity, obesity treatment outcome, and achieved education: A prospective cohort study. J. Adolesc. Health 2017, 61, 508-513. [CrossRef]

46. Wang, B.; Guo, W.; Zhou, C. Selective enhancement of attentional networks in college table tennis athletes: A preliminary investigation. Peer] 2016, 4, e2762. [CrossRef]

47. Larkin, P.; Mesagno, C.; Berry, J.; Spittle, M.; Harvey, J. Video-based training to improve perceptual-cognitive decision-making performance of Australian football umpires. J. Sport. Sci. 2018, 36, 239-246. [CrossRef]

48. Gonçalves, E.; Noce, F.; Barbosa, M.A.M.; Figueiredo, A.J.; Hackfort, D.; Teoldo, I. Correlation of the peripheral perception with the maturation and the effect of the peripheral perception on the tactical behaviour of soccer players. Int. J. Sport. Exerc. Psychol. 2020, 18, 687-699. [CrossRef]

49. Ryan, J.P.; Atkinson, T.M.; Dunham, K.T. Sports-related and gender differences on neuropsychological measures of frontal lobe functioning. Clin. J. Sport Med. 2004, 14, 18-24. [CrossRef] [PubMed]

50. Reigal, R.E.; Hernández-Mendo, A.; Juárez-Ruiz de Mier, R.; Morales-Sánchez, V. Physical exercise and fitness level are related to cognitive and psychosocial functioning in adolescents. Front. Psychol. 2020, 11, 1777. [CrossRef] [PubMed]

51. Blanco-Nápoles, A.A.; López-Álvarez, S.A. Estrategia de intervención para la concentración de la atención en esgrimistas [Intervention strategy for attention concentration in fencers]. Rev. Cient. Olimpia 2020, 17, 1207-1221. 